\title{
Acute Nephronia and Renal Abscesses in Children from Quito, Ecuador
}

\author{
Adriana Arnao1,2,3,4*, Maria Augusta Guerrero', Nathaly Arias', Piedad Villacís ${ }^{2}$, Katia Rivas², \\ Mariana Flores $^{2}$, Jhoana Rivera ${ }^{2}$, Jack Saltos ${ }^{2}$, Gloria Soto ${ }^{3}$, Jorge García ${ }^{3}$, Edison Aymacaña ${ }^{4}$, \\ Diego Bonilla4, Marcelo Merizalde ${ }^{4}$, Cristina Garzón ${ }^{2}$
}

${ }^{1}$ Hospital Axxis, Quito, Ecuador

${ }^{2}$ Hospital Vozandes, Quito, Ecuador

${ }^{3}$ Hospital de los Valles, Quito, Ecuador

${ }^{4}$ Hospital Metropolitano, Quito, Ecuador

Email: ^adri_arnao@yahoo.com

How to cite this paper: Arnao, A., Guerrero, M.A., Arias, N., Villacís, P., Rivas, K., Flores, M., Rivera, J., Saltos, J., Soto, G., García, J., Aymacaña, E., Bonilla, D., Merizalde, M. and Garzón, C. (2021) Acute Nephronia and Renal Abscesses in Pediatric Patients from Quito, Ecuador. $A d$ vances in Infectious Diseases, 11, 375-383. https://doi.org/10.4236/aid.2021.114034

Received: October 6, 2021

Accepted: November 21, 2021

Published: November 24, 2021

Copyright $\odot 2021$ by author(s) and Scientific Research Publishing Inc. This work is licensed under the Creative Commons Attribution International License (CC BY 4.0).

http://creativecommons.org/licenses/by/4.0/

\section{Open Access}

\begin{abstract}
Renal abscess and nephronia are uncommon diseases in children and with unknown global prevalence. Nephronia represents an intermediate state between pyelonephritis and renal abscess. Prompt diagnosis is important to prevent morbidity and mortality (sepsis, renal injury, death). Scientific advances have made these entities more evident, although they may still be underdiagnosed. Patients with this disease require prolonged intravenous antibiotic therapy and potentially surgical resolution, mostly when their size is bigger than $3-5 \mathrm{~cm}$ when therapy with intravenous antibiotics alone fails and they are accessible to percutaneous drainage. We describe five cases of pediatric patients from four private hospitals in Quito, Ecuador followed during a one-year period. In every case, the diagnosis was suspected mostly because of persistent fever, abdominal pain, severe leukocytosis and/or elevated inflammation biomarkers. Only one of them had a previous history of urinary tract malformation while in another one malformation was revealed in his actual admission. Every case had microbiologic isolation. All of them recovered successfully. To our knowledge, in our country, there are no previous reports of these diseases in pediatric patients, and worldwide, there is scarce data. Our aim is to alert doctors who work with children to be aware of this condition.
\end{abstract}

\section{Keywords}

Infectious Diseases, Kidney, Pediatric Nephrology, Nephronia, Renal Abscess, Ecuador 


\section{Introduction}

Renal abscess is an uncommon disease in children, and with unknown global prevalence [1] [2] [3] [4] [5]. Scientific advances have made this entity more evident, although they may still be misdiagnosed [6] [7] [8]. Acute lobar nephronia (ALN), also termed acute focal nephritis or acute focal bacterial nephritis, is a severe, non-liquefactive, localized infection (of the interstitium of the parenchyma in the kidney) involving one or more of the renal lobes [9], and it is considered an intermediate state between acute pyelonephritis and renal abscess [8] [10] [11].

Both (renal abscess and ALN) represent severe infections of renal parenchyma that can lead to renal insufficiency and death [1]. The diagnosis is usually challenging, even more in young children, who usually have unspecific symptoms [12]. Most patients have prolonged fever (for more than 7 days) and abdominal flank pain [10] [13]. They may result from a hematogenous spread or ascending from a urinary tract infection [1]. Frequently, they appear in patients with urinary tract malformation, immunodeficiency or previous history of trauma [2] [4] [14]. They are 3 times more frequent in boys than in girls, mostly unilateral, and on the right-side [2] [3]. Responsible pathogens are gram-negative bacilli (mainly Escherichia coli and Klebsiella pneumoniae), Staphylococcus aureus and anaerobes [1] [3] [5] [6] [13]. The diagnosis requires image studies, ideally computed tomography with medium contrast, although ultrasound is also useful [1] [2] [8] [14]. Percutaneous drainage may be needed when the abscess size is 3 $\mathrm{cm}$ or bigger, or when intravenous antibiotic therapy alone fails [1] [2]. The optimal duration of antibiotic therapy has not been established, but mostly $3-4$ weeks have been used successfully [1] [10] [15]. Diagnosis delay increases morbidity and mortality [1] [4]. The objective of this study is to publically speak about this pathology to avoid morbidity and mortality in children, due to the lack of national and international epidemiological data.

\section{Case Reports}

We describe 5 cases of pediatric patients with acute lobar nephronia and renal abscess attended in 4 private hospitals from Quito-Ecuador from October 2019 to October 2020. We collected data from medical records. Study variables were: age, gender, symptoms, laboratory reports, imaging reports, microbiologic isolations, use of antibiotics, number of days in hospital, and survival status.

\subsection{Case 1}

A previously healthy 5-year-old girl was admitted to the emergency department with a 20-day fever history. She was diagnosed with urinary tract infection without having a positive urine culture, and was subsequently treated with oral cefuroxime, then diagnosed with upper respiratory tract infection, and treated with azithromycin. However, the fever persisted, hence at the emergency room a urine microscopy test was done, and as a result, she got a diagnosis of urinary 
tract infection, was given intravenous ceftriaxone and amikacin. After 48 hours she was still febrile, with leukocytosis, neutrophilia, elevated procalcitonin (PCT) and C reactive protein (CRP) (shown in Table 1), antibiotic therapy was changed to ertapenem, an ultrasound revealed bilateral nephron and a $12 \mathrm{~mm}$ abscess in the upper right kidney (shown in Figure 1). Urine culture was positive to: E. coli susceptible to: cephalosporins, carbapenems, blood cultures were negative. She completed 14 days of intravenous antibiotics and was discharged with 7 extra days of cefuroxime. Voiding cystourethrography (VCUG) remained pending. She did not come back to follow up during the Covid-19 pandemic.

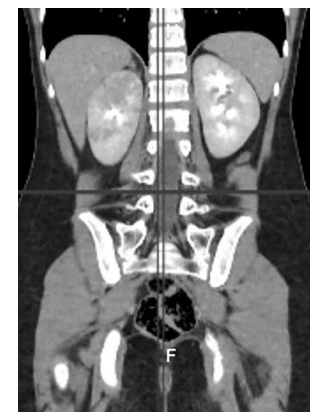

Case 1

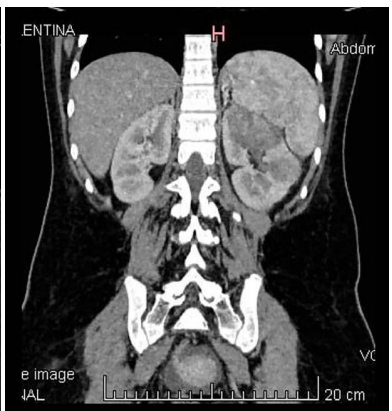

Case 2

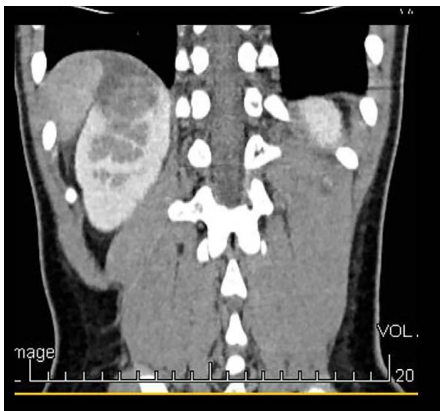

Case 3

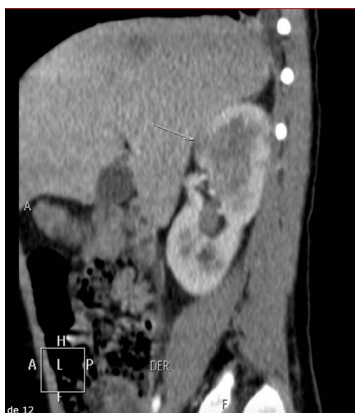

Case 4

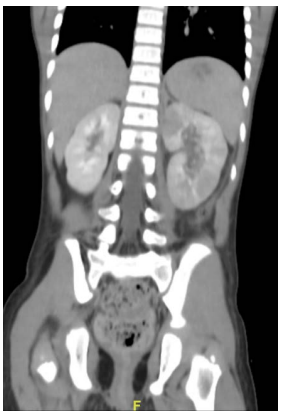

Case 5

Figure 1. Tomographic findings of 5 patients with renal abscess and/or nephronia. Case 1: Cortical zones with hypoperfusion, not well defined in the upper pole of right kidney, consistent with areas of nephronia. Case 2: Renal abscess information in the upper right pole two zones of nephronia in the middle and lower third of right kidney. Case 3: Signs suggestive of left pyelonephritis with abscesses information in the upper left pole. Case 4: Hypodense areas of nephronia in the right kidney. Case 5: Multiple hypodense areas that does not increase with contrast are suggestive of nephronia in the left kidney.

Table 1. Laboratory features of patients with nephronia and renal abscess.

\begin{tabular}{|c|c|c|c|c|c|}
\hline Laboratory & Case 1 & Case 2 & Case 3 & Case 4 & Case 5 \\
\hline Age in years and gender & 5 , female & 10 , male & 13 , female & 9, male & 4 , female \\
\hline Leukocytes K/uL most elevated value & 19.37 & 30.66 & 19.74 & 13.08 & 5.94 \\
\hline $\mathrm{CPR} \mathrm{mg} / \mathrm{L}$ most elevated value & 151 & 72.87 & 319 & 162.3 & 325.34 \\
\hline PCT ng/ml most elevated value & 20.6 & 5.94 & 1.31 & 17.57 & 4.58 \\
\hline Microbiological isolation & $\begin{array}{l}\text { Urine: } \\
\text { Escherichia } \\
\text { coli }\end{array}$ & $\begin{array}{l}\text { Urine: blood and } \\
\text { abscess: } \\
\text { Enterococcus faecalis }\end{array}$ & $\begin{array}{l}\text { Urine: } \\
\text { Escherichia } \\
\text { coli }\end{array}$ & $\begin{array}{l}\text { Urine: } \\
\text { Enterobacter cloacae }\end{array}$ & $\begin{array}{l}\text { Urine: } \\
\text { Escherichia coli }\end{array}$ \\
\hline
\end{tabular}

$\mathrm{CPR}=\mathrm{C}$ reactive protein, $\mathrm{PCT}=$ procalcitonin . 


\subsection{Case 2}

A 10-year-old boy came to the emergency room because he was febrile, with a temperature of $39.7^{\circ} \mathrm{C}$ for 36 hours, accompanied by abdominal pain in the hypochondrium and right flank. He had leukocytosis, elevated PCT and CPR (shown in Table 1), and presented abnormal urine microscopic exam. Ceftriaxone was initiated. His mother was an alcoholic and a drug abuser, and as a consequence, he had been given in adoption several years before and his personal medical history was not detailed. After 48 hours, abdominal pain was still very important, so hepatic abscess was suspected, and metronidazole was added. Abdominal computed tomography showed abscesses in the upper right kidney and 2 zones of nephronia of the middle and inferior third in the same kidney (shown in Figure 1). Blood and urine cultures were positive to Enterococcus faecalis susceptible to ampicillin (urine $1.000 \mathrm{CFU} / \mathrm{ml}$ ). Antimicrobial therapy was adjusted to ceftriaxone and ampicillin. Five days later he was still febrile, with abdominal pain, so he went through diagnostic and therapeutic CT-guided percutaneous drainage. E. faecalis was also reported from the abscess. He completed 14 days of intravenous antibiotics and was discharged from hospital with oral amoxicillin for 7 more days. VCUG revealed right double pyelocaliceal system, bilateral diverticula, bilateral vesicoureteral reflux grade II, so he went successfully through diverticulectomy and bilateral ureteral re-implantation one month later.

\subsection{Case 3}

A previously healthy 13-year-old vegan girl was admitted to the emergency department with a history of 36-hour abdominal flank pain, accompanied by emesis and fever. She was severely dehydrated, was hypotensive, tachycardiac, and febrile. Urine microscopic exam showed no leukocytes nor nitrites. She had leukocytosis, neutrophilia, elevated PCT and CPR (shown in Table 1). Ceftriaxone was initiated. Because of sepsis and no improvement 48 hours later, she was admitted to the intensive care unit where antibiotic therapy was changed to meropenem. Abdominal computed tomography showed multiples zones of nephronia in the upper left kidney (shown in Figure 1). Urine culture from midstream urine was positive to $E$. coli $10.000 \mathrm{CFU} / \mathrm{ml}$, susceptible to: $2^{\text {nd }}$ and $3^{\text {rd }}$ generation cephalosporins, carbapenems, aminoglycosides. Blood cultures were negative. She improved clinically but presented leukopenia and neutropenia, probably due to meropenem, so ceftriaxone and clindamycin were used instead. She completed 7 days of total intravenous antibiotics. Her parents requested hospital discharge because of economic issues. She was HIV negative, her immunoglobins and VCUG were normal. She continued antibiotic therapy with cefuroxime and clindamycin by oral route for 14 days more. She continues asymptomatic 4 months later in follow-up.

\subsection{Case 4}

A 9-year-old boy was admitted to the emergency department because of fever, abdominal mesogastric and bilateral flank pain. He had the previous history of 
ureterocele with surgery one year prior to the event. He was diagnosed with pharyngotonsillitis; he received azithromycin without improvement, so he went back to the emergency department. He went through a computed tomography scan to rule out appendicitis, he got a diagnosis of mesenteric adenitis and was discharged with amoxicillin/clavulanic acid. Abdominal pain did not improve, so he went back again to the emergency department. His urine analysis was compatible with an urinary tract infection. He had leucopenia, thrombocytosis, elevated CPR and PCT (shown in Table 1). After 48 hours, he showed signs of sepsis and abdominal pain persisted, hence he went through another computed tomography which showed hypogenic zones in the right kidney which were compatibles with nephronia + lymphangiectasia (shown in Figure 1). Vancomycin was added. 48 hours later, urine culture was positive to Enterobacter cloacae Amp-C, so antibiotic therapy was changed to cefepime alone. He evolved favorably, he completed 14 days of intravenous antibiotic. He went through VCUG, which showed vesicoureteral reflux grade II in the right kidney and grade I in the left kidney + vesico-sphincter disfunction. His urethra-cystoscopy showed severe trabeculae in the whole bladder. He was programmed for surgery but did not come back.

\subsection{Case 5}

A 4-year old girl came to the emergency department because of 4 days of fever. She had a history of chronic constipation. Her urinalysis was compatible with urinary tract infection, so she was discharged home with trimethoprim-sulfamethoxazole. She did not get better as she had diffused abdominal pain so she went back to the emergency room. She had leukocytosis, elevated CPR and PCT (shown in Table 1), so she was admitted to hospital. For persistent abdominal pain and fever, she went through CT and hence nephronia was diagnosed in the left kidney (shown in Figure 1). E. coli was found in urine culture. She received 11 days of intravenous antibiotics (ceftriaxone) and was discharged with oral cefalosporins for a total of 21 days. Urinary tract malformation was ruled out through renal ultrasound and VCUG.

\section{Discussion and Conclusions}

We show five cases of pediatric patients with nephronia and renal abscess in a 1-year period in Quito, attended in four private hospitals. Given the fact that this is not a common disease, and that our city is relatively small-it has three million inhabitants including not only the urban area [16] [17] we consider these are important findings.

Nephronia (ALN) and renal abscess must be considered in the differential diagnosis in all patients with persistent fever, abdominal pain, leukocytosis, elevated inflammation biomarkers and/or torpid clinical evolution [10] [13]. Physicians must think of these entities and know that ALN represents an intermediate state between pyelonephritis and renal abscess. Diagnosis is often difficult because fever, poor general condition, low-back pain, pyuria, bacteriuria, leukocy- 
tosis can mimic simple acute pyelonephritis. Imaging studies must be imperatively used for diagnoses, such as ultrasound or computed tomography, as they can undoubtedly improve outcomes and diminish risks of mortality, sepsis, permanent renal injury [11].

Contrary to other reports, most of our patients were girls, and similarly, the occurrences happened mostly in the right kidney.

It is of outstanding importance to establish a correct diagnosis because the duration of intravenous antibiotic therapy differs substantially, acute pyelonephritis often requires 7 - 10 days of therapy in children, while ALN or renal abscess requires at least 3 weeks, and even sometimes surgical treatment [15].

When percutaneous drainage is needed, in order to diminish radiation exposure, ultrasound-guided must be the preferred method [13], but in one of our patients it was not possible because it was up too high in the right kidney, so it was not easily visible through ultrasound and we had to use computed tomography to guide the procedure.

In our case series, in 3 out of 5 Escherichia coli was found, which is the most frequent bacteria involved [8]. Some studies have shown that $E$. coli found in uroepithelial cells in patients with ALN or renal abscess had more adhesion capacity and were more cytotoxic than the E. coli found in acute pyelonephritis, showing that not only anatomic condition and/or immune status of patients intervene, but also bacteria virulence factors are very important [7].

Antimicrobial stewardship and rational use of antibiotics are important issues. Patients must be properly studied; doctors must have a diagnosis of certainty instead of just changing antibiotics blindly. Mostly, it is not adequate to diagnose urinary tract infection in children without a positive urine culture [18].

It should be noted that these patients were attended during COVID-19 pandemic, so their follow up was not adequate, none of them came back to follow up as indicated

Follow-up with renal scan with mercapto-succinic acid (DMSA) is very important to rule out renal scars and to identify the progression of renal function damage [9].

We pretend to alert doctors of this pathology that could be underdiagnosed and should be suspected in patients with abdominal pain, severe leukocytosis, elevated inflammation biomarkers. The presence of urinary tract malformation always has to be ruled out.

\section{Statements}

\section{Acknowledgements}

We are very grateful for the excellent technical assistance from Dr. Marco Fornassini and Dr. Manuel Baldeón (Universidad Tecnológica Equinoccial).

\section{Statement of Ethics}

The research was conducted ethically in accordance with the World Medical 
Association Declaration of Helsinki. Parents of the patients have given their written informed consent to publish their case (including publication of images). Also, every hospital approved the research. The subject's identities were not revealed.

\section{Funding Sources}

\section{Self-financed.}

\section{Authors' Contributions}

- Adriana Arnao: conception and design of the work; acquisition, analysis, interpretation of data for the work; drafting the work; final approval of the version to be published; agreement to all aspects of the work.

- Maria Augusta Guerrero: acquisition, analysis, and interpretation of data for the work; revising the work, final approval of the version to be published; agreement to all aspects of the work.

- Nathaly Arias: acquisition of data for the work; drafting the work, final approval of the version to be published; agreement to all aspects of the work.

- Piedad Villacís: acquisition, analysis, and interpretation of data for the work; revising the work, final approval of the version to be published; agreement to all aspects of the work.

- Katia Rivas: acquisition, analysis, and interpretation of data for the work; revising the work, final approval of the version to be published; agreement to all aspects of the work.

- Mariana Flores: Analysis, interpretation of data for the work; revising the work.

- Final approval of the version to be published; agreement to all aspects of the work.

- Jhoana Rivera: Analysis, interpretation of data for the work; revising the work.

- Final approval of the version to be published; agreement to all aspects of the work.

- Jack Saltos: Acquisition, analysis, interpretation of data for the work; revising the work.

- Final approval of the version to be published; agreement to all aspects of the work.

- Gloria Soto: Acquisition of data for the work; revising the work, final approval of the version to be published; agreement to all aspects of the work.

- Jorge García: Analysis of data for the work; revising the work, final approval of the version to be published; agreement to all aspects of the work.

- Edison Aymacaña: Analysis of data for the work; revising the work, final approval of the version to be published; agreement to all aspects of the work.

- Diego Bonilla: Analysis of data for the work; revising the work, final approval of the version to be published; agreement to all aspects of the work. 
- Marcelo Merizalde: Analysis of data for the work; revising the work, final approval of the version to be published; agreement to all aspects of the work.

- Cristina Garzón: Acquisition of data for the work; revising the work, final approval of the version to be published; agreement to all aspects of the work.

\section{Conflicts of Interest}

The authors declare no conflicts of interest regarding the publication of this paper.

\section{References}

[1] Chen, C.Y., Kuo, H.T., Chang, Y.J., Wu, K.H., Yang, W.C. and Wu, H.P. (2016) Clinical Assessment of Children with Renal Abscesses Presenting to the Pediatric Emergency Department. BMC Paediatrics, 16, Article No. 189.

https://doi.org/10.1186/s12887-016-0732-5

[2] Bulut, I.K., Mir, S. and Conkar, S. (2016) Renal Abscess in a Previously Healthy 4-Year-Old Girl: A Case Report. Pediatric Urology Case Reports, 3, 170-175. https://doi.org/10.14534/PUCR.2016520782

[3] Comploj, E., Cassar, W., Farina, A., Gasparella, P., Trenti, E., Palermo, S., et al. (2013) Conservative Management of Paediatric Renal Abscess. Journal of Pediatric Urology, 9, 1214-1217. https://doi.org/10.1016/j.jpurol.2013.05.016

[4] Cancelinha, C., Santos, L., Ferreira, C. and Gomes, C. (2014) Renal Abscesses in Childhood: Report of Two Uncommon Cases. BMJ Case Reports, 2014, bcr2013202408. https://doi.org/10.1136/bcr-2013-202408

[5] Kaye, J.D., Wyly, J., Kirsch, A.J., Figler, B.D., Healy, K.A., Healy, K.A., et al. (2009) Renal Abscess in the Pediatric Population: Diagnostic and Management Recommendations Based on a Large Institutional Experience. The Journal of Urology, 181, 379. https://doi.org/10.1016/S0022-5347(09)61072-7

[6] Lucas García, J., Oltra Benavent, M., Ferrando Monleón, S., Marín Sierra, J., Rabasco Álvarez, M.D., Benito Julve, P., et al. (2020) Predictive Markers of Acute Focal Bacterial Nephritis. A Multicentre Case-Control Study. Anales de Pediatría, 93, 77-83. https://doi.org/10.1016/j.anpedi.2020.01.018

[7] Cheng, C.H., Su, L.H., Tsau, Y.K. and Lin, T.Y. (2011) Comparison of Virulence Variations on MDCK Monolayers by Escherichia coli Isolated from Acute Lobar Nephroma and Acute Pyelonephritis. New Microbiologica, 34, 65-72.

[8] Chen, W.L., Huang, I.F., Wang, J.L., Hung, C.H., Huang, J.S., Chen, Y.S., et al. (2015) Comparison of Acute Lobar Nephronia and Acute Pyelonephritis in Children: A Single-Center Clinical Analysis in Southern Taiwan. Pediatrics \& Neonatology, 56, 176-182. https://doi.org/10.1016/j.pedneo.2014.08.002

[9] Masood, Y., Hussain, I., Khan, U., Khalid, M.U. and Javed, M.U. (2021) Acute Lobar Nephronia in an Infant Presented as a Renal Tumor. Urology Case Reports, 34, Article ID: 101450. https://doi.org/10.1016/j.eucr.2020.101450

[10] Granados, M.A., Espino, H.M., Gancedo, B.A., Albillos, M.J.C., Álvarez-Cortinas, J.F. and Molina, A.C. (2007) Nefronía focal aguda bacteriana: Diagnóstico, tratamiento y evolución. Anales de Pediatría, 66, 84-86. https://doi.org/10.1157/13097366

[11] Yang, C.C., Shao, P.L., Lu, C.Y., Tsau, Y.K., Tsai, I.J., Lee, P.I., et al. (2010) Comparison of Acute Lobar Nephronia and Uncomplicated Urinary Tract Infection in Children. Journal of Microbiology, Immunology and Infection, 43, 207-214. 
https://doi.org/10.1016/S1684-1182(10)60033-3

[12] James, C., Harrison, G.J., Kaplan, S.L., Steinbach, W.J. and Hotez, P.J. (2018) Feigin and Cherry's Textbook of Pediatric Infectious Diseases. Eight Edition, Elsevier, Houston, 4018 p.

https://www.elsevier.com/books/feigin-and-cherrys-textbook-of-pediatric-infectiou s-diseases/unknown/978-0-323-39281-5

[13] Fernandes, R.C.S.C. and Duarte, P.D.A.C. (2002) Perinephric and Renal Abscesses in Children: A Study of Three Cases. Revista do Instituto de Medicina Tropical de São Paulo, 44, 341-344. https://doi.org/10.1590/S0036-46652002000600009

[14] Halm, B.M. (2019) Diagnosis of an Acute Lobar Nephronia in the Emergency Department Using Point-of-Care Ultrasound. Journal of Emergency Medicine, 57, 227-231. https://doi.org/10.1016/j.jemermed.2019.04.030

[15] Hosokawa, T., Tanami, Y., Sato, Y. and Oguma, E. (2020) Comparison of Imaging Findings between Acute Focal Bacterial Nephritis (Acute Lobar Nephronia) and Acute Pyelonephritis: A Preliminary Evaluation of the Sufficiency of Ultrasound for the Diagnosis of Acute Focal Bacterial Nephritis. Emergency Radiology, 27, 405-412. https://doi.org/10.1007/s10140-020-01771-8

[16] INEC (2013) Proyecciones Poblacionales [Internet]. Instituto Nacional de Estadísticas y Censos (INEC). https://www.ecuadorencifras.gob.ec/proyecciones-poblacionales

[17] Carvajal, A.M. (2019) Quito se convirtió en la ciudad más poblada del Ecuador con más de 3 millones de habitantes en el 2018. El Comer [Internet].

https://www.elcomercio.com/actualidad/orden-movilidad-desafios-candidatos-alcal dia.html

[18] Korbel, L., Howell, M. and Spencer, J.D. (2017) The Clinical Diagnosis and Management of Urinary Tract Infections in Children and Adolescents. Paediatrics and International Child Health, 37, 273-279. https://doi.org/10.1080/20469047.2017.1382046 